\title{
Different Perspectives of Psychiatry Within Two Neighboring Residency Training Programs
}

\author{
Bruce Rosenblum, MD \\ Sheppard and Pratt Hospital, Baltimore Maryland
}

Follow this and additional works at: https://jdc.jefferson.edu/jeffjpsychiatry

Part of the Psychiatry Commons

\section{Let us know how access to this document benefits you}

\author{
Recommended Citation \\ Rosenblum, MD, Bruce (1986) "Different Perspectives of Psychiatry Within Two Neighboring Residency \\ Training Programs," Jefferson Journal of Psychiatry. Vol. 4 : Iss. 2 , Article 7. \\ DOI: https://doi.org/10.29046/JJP.004.2.004 \\ Available at: https://jdc.jefferson.edu/jeffjpsychiatry/vol4/iss2/7
}

This Article is brought to you for free and open access by the Jefferson Digital Commons. The Jefferson Digital Commons is a service of Thomas Jefferson University's Center for Teaching and Learning (CTL). The Commons is a showcase for Jefferson books and journals, peer-reviewed scholarly publications, unique historical collections from the University archives, and teaching tools. The Jefferson Digital Commons allows researchers and interested readers anywhere in the world to learn about and keep up to date with Jefferson scholarship. This article has been accepted for inclusion in Jefferson Journal of Psychiatry by an authorized administrator of the Jefferson Digital Commons. For more information, please contact: JeffersonDigitalCommons@jefferson.edu. 


\title{
Different Perspectives of Psychiatry Within Two Neighboring Residency Training Programs
}

\author{
Bruce Rosenblum, M.D.
}

This paper arises out of my fortunate opportunity to observe two very different psychiatric residency training programs. While a fourth-year resident at a large, psychodynamically-oriented private psychiatric hospital, I was able to do a consultation liaison rotation at a neighboring academic institution at the vanguard of biological psychiatry. I left the familiar, well-manicured suburban grounds for the inner city of Baltimore to be one of the first experiments in "cross-fertilization" between these residency training programs. Although the two institutions are located in the same city and stem from the early history of American psychiatry, they have been worlds apart in their approach. The hospitals have distinct development histories. The private hospital was originally founded by a philanthropic Quaker, Moses Sheppard, before the Civil War. He wished to provide a humane asylum for treatment of the mentally disturbed. In the context of the enlightened ideas of Pineal and The Moral Treatment, he believed that separating the patients from chaotic family and social influences and providing a respectful and humane environment would help restore sanity. Sheppard instructed that all cells for patients were to be above ground and have windows. Enoch Pratt, a successful businessman, later made a large contribution to what is now known as The Sheppard and Enoch Pratt Hospital. The academic center was established out of a growing interest in research, training, and in returning psychiatry to the field of medicine. Under the direction of Adolf Meyer in 1913, the Henry Phipps Psychiatric Clinic at Johns Hopkins Hospital was founded. Many advances in psychosocial theory and biological research continue to be achieved at this internationally renowned medical center.

The major distinction which subsumes most of the others in distinguishing the two institutions is that of a medical model versus a developmental biopsychosocial approach. ${ }^{1}$ This difference was concretely played out in my anxieties about my attire. I had difficulty even imagining it: "Do they really wear white coats? What would that do to the transference?" I did not even own a full-length white coat (though I had for some time wanted one, especially with red stitching

Dr Rosenblum wrote this paper while a fourth-year resident at the Sheppard and Pratt Hospital, Baltimore, Maryland.

${ }^{1}$ Specifying the curriculum at each institution is beyond the scope of this paper; this information can be obtained from the residency training directors of these programs. 
spelling out my name). After several days of being the only resident wearing a sports coat, I felt like a fish out of water. I realized that my credibility would be enhanced (from zero) both with the psychiatric residents and the doctors of other specialties if I donned a white coat. When in Rome. . . .

Initial encounters were curious. One resident approached me saying that he had heard that at Sheppard-Pratt we were using insufficient, homeopathic amounts of Haldol ${ }^{\circledR}$. I jokingly told him that we did not use Haldol ${ }^{\circledR}$ at all but preferred to have our psychotic patients drink rhubarb tea. ${ }^{2}$ Within the first few weeks at Hopkins, I found myself overcompensating for my origin by researching and photocopying inordinate amounts of research and scientific literature concerning the patients I saw. I was welcomed as somewhat of a curiosity.

Along with this emphasis on the medical model came discussions of form versus content of symptoms. For example, a person hearing voices which tell him to poke out his eyes is suffering from an abnormal form, that is, auditory hallucinations, the content of which is to blind himself. The biological institution stressed that the form must be recognized and treated as the primary abnormality. They tended to jovially ridicule those more psychodynamically minded for attributing major significance to the content of hallucinations or delusions. The dynamic analytic perspective however would consider the meaning of the content, in terms of compromise formation between conflicting agencies of the mind, as being of primary importance in bringing about the aberrant symptomatic form. Furthermore, a fixation, regression, or missed step in the maturation of the psyche due to trauma or chaotic object relations is used as an explanatory model in deciphering the meaning of the symptom. Fortunately, considerable overlap occurs in the actual treatment. Neuroleptics are utilized in the dynamically-oriented hospital to treat the form of the symptoms, and some attention is given to the significance of the content of the symptom in the academic setting.

With symptomatic form or phenomenology being of primary significance, the cross-sectional mental status examination takes on a paramount importance. Thus, another important distinction in emphasis is on the cross-sectional view of the patient versus a more longitudinal view. This is one of several variables reflected in the difference between the average length of stays between institutions, from a week or two at the university hospital versus many months at the private hospital. Although Sheppard-Pratt has short-term and intermediate stay units, chronic schizophrenic, character disordered, and affectively disturbed patients, oftentimes with a prior history of many short-term hospitalizations, are commonly treated for over a year on an inpatient basis. More dynamicallyoriented residents at Sheppard-Pratt are astonished at what they see as harsh, incomplete, "patch-up" short-term hospitalizations. Residents at the academic

\footnotetext{
${ }^{2}$ Psychopharmacologic medications are used regularly at Sheppard-Pratt though the long-term units frequently treat patients who have responded poorly to multiple trials on adequate doses of different groups of medication.
} 
setting cannot imagine what more could be accomplished by an expensive, long-term hospitalization, and question the lack of controlled outcome studies. It should be noted that the lengths of stay are partially determined by patient population and financial restraints. At Sheppard-Pratt, much pride is taken in a comprehensive approach to the whole person over an extended period of time. Yet, long-term changes in personality structure and function are difficult to measure and do not readily lend themselves to comparison with control groups.

Another major distinction of emphasis between the two institutions relates closely to the differences in treating the cross-section versus the longitudinal functioning of the patient. This can best be described as a distinction between treating the state or trait. At Sheppard-Pratt, there is considerable suspicion about merely treating the cross-sectional state. For instance, we sometimes observe borderline patients experiencing a psychotic episode after months of inpatient treatment. We frequently see regressions and progressions in psychotic symptomatology in schizophrenics and bipolar patients. Thus, less emphasis is placed on the immediate state, and energies are spent on helping the patient alter long-standing self-defeating patterns of behavior.

The state of mind, however, is more easily modified with our present technology and is more clearly connected with clinical syndromes, biological abnormalities, and genetic vulnerabilities. The state of mind is more closely tied to phenomenological abnormalities as reported by the patient and as behaviorally observed. Thus, phenomenology is emphasized over psychodynamics at the academic institution. This approach has allowed more discreet diagnostic categories of syndromes to emerge and to be described. Although this development is extremely important, overemphasis on descriptive phenomenology seems to result in a loss of the comprehensiveness that the analytic model offers for understanding the patient, their life history, and implications for working through conflicts and modifying maladapted patterns of gratification. It does, however, allow one to separate what is more easily and verifiably treatable.

While at $\mathrm{JHH}$, if I became bogged down in the possible dynamics at work in a patient's psychopathology, an attending might ask, "Does the patient have symptoms consistent with the syndrome of major depression or not?" This perspective, I came to learn, is often helpful in distancing oneself from the chaos of projective identification and countertransference states. It helps distinguish what interventions can be initiated and what may be beyond the scope or limitations of the clinical setting. Yet, what stands in the balance are countertransference feelings that can be valuable in understanding the patient's affective experience and in discerning what the patient needs to hear in order to grow. The innumerable therapeutic aspects of an engaging long-term therapistpatient relationship can also be lost.

It is my impression that it is vitally important for psychiatric residents and psychiatrists to learn both a phenomenological approach as well as what is known about the interaction of the patient and the doctor in psychotherapy. A purely phenomenological perspective is impossible, as the observer changes the 
subject by his very presence and theoretical model. Understanding psychotherapy is important not only from the view of helping the patient, but also in enabling the therapist to engage with the patient in intensive psychotherapy without being adversely affected himself. It is critical for the therapist to be familiar with the experience and theory of projective identification. At Sheppard-Pratt, residents are closely supervised in their psychotherapeutic work with inpatients where gross and primitive aspects of the patient are often projected onto and experienced by the therapist. The therapist must come to recognize this process and return these affects to the patient in a more worked-through form. Should this subtle but ubiquitous process not be a part of a psychiatrist's working vocabulary, he can come to identify with the primitive projections and not have the theoretical framework and clinical skills to pull himself out.

Differences are also apparent regarding the authority of the doctor. In the medical model the hierarchy is clear. The doctor is visibly identified, with a long white coat, as the person ultimately responsible for directing patient care. Decisions tend to flow from the top down. Roles and division of labor are more specialized. Given the conventional civilian dress at Sheppard-Pratt, the symbols of authority are more subtle. The treatment team concept is emphasized and although the doctor is responsible for the final decisions, all staff members take part in expressing their reactions, observations, and quality of interpersonal dealings with the patient. Much insightful information can be gleaned about the patient and then utilized for more potent psychoeducation, therapy, and milieu management. A shortcoming of the team approach involves an inevitable drifting of responsibilities and confusion around the decision-making process.

Another difference which relates to the medical model was evident in the particular styles of teaching. At the academic institution, it was a teaching through intimidation, or more benignly, through challenge. It is a system familiar to most physicians from their experience in medical school. It consists of "calling on" a subordinate with a direct question to test his knowledge, particularly in his area of supposed expertise. I had ambivalent reactions to this method. I was stimulated by the impressive exchange of information and yet cringed at the competitive and demeaning aspects. It should be noted that there is often a fraternal/paternal playfulness involved in this method.

Teaching at Sheppard-Pratt is more directly encouraging. Although the demands of the program are quite rigorous, residents seem to be nurtured along in their personal and professional endeavors. Both institutions have stimulating didactic programs, though the content of each reflects their differing perspectives.

Though I have drawn various distinctions between the perspectives at each institution and have attempted to point out advantages and disadvantages involved with each, it should be clear that they are distinctions in emphasis and not in absolute values. Each institution has developed a complex paradigm in attempting to understand psychopathology. These models are influenced by the 
unique developmental histories of the institutions and the current economic and social conditions. While each feels that their approach is most justified, the methods for reaching these conclusions are based on quite different models of confirmation. A certain fanaticism or focused attention about a given model appears essential for research and advancement of theory.

It is my impression that an interchange of residents could be helpful to each institution. The residents at Sheppard-Pratt could benefit from a healthy dose of the medical model type of critical thinking. They would also benefit from finely tuning their mental status exams and more clearly classifying the phenomenologic descriptions and syndromes inherent in psychiatric illness. Other advantages include exposure to a multidisciplinary general hospital and state-ofthe-art biological technology. The Hopkins residents could benefit from the intense involvement in psychotherapy with severely disturbed individuals over an extended period of time. Time should be sufficient not only for an understanding of the patient through an analytic, object relations, dynamic, developmental model but also to observe the effects of a multidimensional approach. Even psychopharmacologic interventions involve some trial and error, and response is best observed over a period of several months, particularly with this population of complex treatment-resistant patients.

The paradigms described are not only contrasting within these two residency training programs but within the field of psychiatry as a whole. It is the job of every psychiatrist, particularly during the critical period of residency, to sift through a variety of approaches and sort out a style and viewpoint which he finds is most helpful to patients. This purpose can only be served by a comprehensive, diverse exposure to differing perspectives within psychiatry. Baltimore is particularly fortunate to have two very different institutions with rich educational experiences to offer their psychiatric residents. 